\title{
Physiological Adaptation in Women Presenting Fibromyalgia: Comparison with Healthy Controls
}

Elvira Lange ${ }^{1}$, Kaisa Mannerkorpi ${ }^{1}$, Asa Cider ${ }^{1}$, Trevor Archer ${ }^{2}$ and Kerstin Wentz ${ }^{3^{*}}$

${ }^{1}$ Institute of Neuroscience and Physiology, University of Gothenburg, Sweden

${ }^{2}$ Department of Psychology, University of Gothenburg, Sweden

${ }^{3}$ Occupational and Environmental Medicine, Sahlgrenska University Hospital, Sweden

\begin{abstract}
Objective: To compare the heart rate variability (HRV) before and after a sub-maximal exercise test in women with fibromyalgia (FM) and to compare the result to matched controls. Additionally, to compare heart rate (HR) before, during and after the sub-maximal exercise test.
\end{abstract}

Methods: Twenty-four women with FM and 26 controls performed a sub-maximal exercise test. HRV was registered for 5 minutes at rest before and after the exercise test. HR was registered at baseline, during the exercise test and at recovery.

Results: The HRV of the healthy group was statistically different from the exercise test but the women with FM showed no such difference. HR was significantly higher among the women with FM than in the healthy group at baseline and up to $75 \mathrm{~W}$ but lower at peak $(138 / 152 \mathrm{bpm}, \mathrm{p}<0.008)$. In women with FM HR during exercise $(\mathrm{HR} 2)$ was predicted by heart rate recovery (HRR20) and physical exertion (RPE2). HRR20 and RPE2 accounted for 0.465 of the variance $(p=0.006)$ in HR2. In healthy women HR2 correlated with HRR20 and negatively with physical activity $(\mathrm{PhA})$. In the reference group HRR20 and PhA accounted for $0.448(p=0.002)$ of the variance HR.

Conclusion:The HRV in women with FM show less adjustment of the ANS while not being significantly affected by submaximal exercise as healthy women. In healthy women heart rate during the test was negatively related to PhA. In women with FM exertion seems to replace an effect from exercise on physiological adaptation. FM may entail imperceptible extraction of power from PhA while under load. Links to FM pain will be discussed.

Women with FM seem to rate exertion "Very hard" on lower workload and HR than healthy women. The physiotherapeutic methodology for measuring HRV with basic HR monitors should be improved before it can be recommended for clinical use.

Keywords: Fibromyalgia; Bicycle ergometer test; Heart rate variability; Cardiac response; Physiotherapy

\section{Introduction}

Fibromyalgia (FM) presents a pain syndrome that affects $2-3 \%$ of the population in Sweden and is generally more common among women than among men [1]. The primary symptom of FM is the experience of widespread pain in all four quadrants of an individual's body. The diagnosis is set using the criteria developed and outlined by the American College of Rheumatology, that include pain duration (>three months) and pain localization ( $\geq 11 / 18$ tender points) [2].

Several studies have shown changes in the autonomous nervous system (ANS) of individuals presenting FM that are manifested as sympathetic hyperactivity and parasympathetic hypoactivity $[3,4]$. No specific test may solely measure autonomic function but the registration of heart rate variability (HRV) is a non-invasive method that detects changes in the parasympathetic branch of ANS and in the balance between sympathetic and parasympathetic activity. HRV is the variation in time between heartbeats and is based on the time between the $\mathrm{R}$ waves in the electrocardiogram [5]. HRV is measured for several different parameters and in individuals presenting FM. These parameters are deviant and lower in comparison with the HRV observed in healthy reference persons $[3,6,7]$. Parasympathetic hypoactivity in women with FM may be detected through HRV measurements and has been associated with poor sleep quality $[5,8]$ and chronic fatigue syndrome [9]. Further, HRV parameters correlate with pain severity and depression [4].
Exercise therapy has a positive effect on FM including reduction of pain and depression, improved physical functioning and global health [10]. Physical exercise improves symptoms and quality-of-life but does not alter the autonomic modulation [11]. Nijs et al. [12] concluded that exercise as a prescription requires finesse. Physical therapists may contribute this finesse and guide persons with FM to activation self-management $[12,13]$. In healthy subjects, HRV has been used to optimize exercise load and increased knowledge about HRV in FM could optimize physical therapy exercise interventions [3].

Changes in ANS may cause also disturbances in the ability to regulate heart rate (HR). These disturbances are termed chronotropic incompetence referring to the inability of the heart to increase its rate commensurate with increased activity or demand as required with physical exertion [14]. It produces exercise intolerance which impairs quality-of-life [15]. Attempts to study ANS through HR-response

*Corresponding author: Kerstin Wentz, Occupational and Environmental Medicine, Sahlgrenska University Hospital, Sweden, Tel: +46 [0]31 786 3219; Fax: + [0]31 409728; E-mail: kerstin.wentz@amm.gu.se

Received: January 11, 2017; Accepted: January 28, 2017; Published: February 09, 2017

Citation: Lange E, Mannerkorpi K, Cider A, Archer T, Wentz K (2017) Physiological Adaptation in Women Presenting Fibromyalgia: Comparison with Healthy Controls. Clin Exp Psychol 3: 147. doi: 10.4172/2471-2701.1000147

Copyright: ( 2017 Lange E, et al. This is an open-access article distributed under the terms of the Creative Commons Attribution License, which permits unrestricted use, distribution, and reproduction in any medium, provided the original author and source are credited. 
during exercise tests in women presenting FM have shown, compared to healthy persons, a reduced HR-response during strenuous exercise on a bicycle $[16,17]$. HR recovery is slower in persons with FM than in healthy controls following a maximal exercise test [6]. HRV has not been studied at recovery from submaximal exercise in women with FM.

\section{Aim}

The main purpose of the present study was to investigate the baseline values and the response of HRV after an incremental, aerobic submaximal exercise test in female patients presenting FM and to compare the result to a gender- and age-matched healthy control group. The ancillary purpose was to study HR before, during and after the exercise exertion test in both groups.

\section{Methods}

\section{Subjects}

Recruitment: Twenty-five women presenting FM were recruited from primary health care and rehabilitation centres in the region of Västra Götaland (Sweden) all of whom had expressed as interest in participating in the study. The healthy control group was recruited primarily from employees (volunteers) within the health care service, but was complemented with other volunteers in order to obtain for the distribution of age and education level to match that of the women with FM. The age match was made pairwise \pm 3 years.

Inclusion: Inclusion criteria were female participants, aged 20-60 years with a registered FM diagnosis within the last 7 years.

Exclusion: Exclusion criteria were prior trauma to the head, brain damage, severe somatic disease, muscular disease, heart disease or anemia, dependent in personal activities of daily life as well as drugs affecting HR

The healthy control group were required to confirm their healthy status, and the same exclusion criteria as for the FM patients were used, with one addition: prolonged pain.

\section{Study design}

This was a cross-sectional study comparing two groups and is part of a larger study, "Affective, cognitive and defensive interplay in fibromyalgia: from premorbid strain to treatment of somatic manifestations". The study protocol was approved by the Regional Ethical Review Boards at the University of Gothenburg and was designed according to the Declaration of Helsinki, revised 1983. Informed consent was obtained from all the participants prior to the study.

Procedure: The attending physician for each woman presenting FM was contacted to confirm the FM diagnosis and to certify their appropriateness for inclusion in the study. Demographic data was collected through questionnaires sent to the home of each participant along with questionnaires about quality of life and physical activity. Participants were assigned to a rehabilitation center to perform a submaximal exercise test. In conjunction with the test, body weight and height were registered.

Characteristics: Current pain, on a visual analog scale (VAS) 100 $\mathrm{mm}$, was measured before the test to characterize the women with FM, together with the questionnaires regarding quality of life and physical activity levels.

To assess quality of life the Short-Form 36 (SF 36) was used. The SF 36 measures health on eight different subscales and is summarized on one physical and one mental health scale ranging between 0 and 100 where a higher value represents a higher estimated quality of life [18]. SF 36 has showed to be an appropriate instrument for assessing quality of life in women presenting FM [19].

The Godin Leisure-Time Exercise Questionnaire and The SaltinGrimby Physical Activity Level Scale were used to evaluate physical activity and $[20,21]$. The latter consists of one question about physical activity the last three months with four answer choices. It has been found to have good validity and reliability in an adult, Swedish sample [22].The Godin Leisure-Time Exercise Questionnaire assessed leisure time exercise behaviour and gives a value calculated from time and activity level per week. It presents a question regarding the frequency of sweat-inducing activities. The questionnaire has been tested with satisfactory results for reliability and validity [23].

Submaximal exercise test: Subjects performed a stepwise load increment submaximal exercise test on an electronically braked cycle ergometer (839 E, Monark, Vansbro, Sweden) to the very hard perceived exertion level. The testing was conducted at the same time of day (afternoon) at least 3 hours after the last meal or coffee and the participants were asked to avoid smoking prior to the test. Before the exercise test, HRV was recorded for 5 minutes during a supine rest. HRV was recorded by a Polar RS 800CX heart rate monitor (Polar electro, Kempele, Finland) that performs HRV recordings satisfyingly compared with an ambulatory electrocardiography system [24]. HR and blood pressure was measured after 10 minutes of supine rest. HR was registered from the heart rate monitor and blood pressure was taken manually with stethoscope (Littmann Classic II S.E., 3M, St. Paul, Minnesota) and sphygmomanometer (Welch Allyn, Inc., Skaneateles Falls, New York, USA). HR, blood pressure and rating on the Borg RPE scale (rating of perceived exertion) was collected during the submaximal test that started at a workload of $25 \mathrm{~W}$ and was increased with $25 \mathrm{~W}$ each 4 minutes. When the subject responded with 17 (very hard) on the Borg RPE scale, she was asked to carry out the remaining minutes at the present workload if possible [25]. Directly after the test the subjects had 20 minutes of supine rest during which HR and blood pressure was measured after $1,2,4,10,15$ and 20 minutes and HRV was recorded for the last 5 minutes. Blood pressure is not currently presented as an outcome.

\section{Data analysis}

The RR-interval was analyzed with the computer program Kubios HRV 2.1 (Biosignal Analysis and Medical Imaging Group, Joensuu, Finland). Analyses were conducted according to conventional methods in both time domain and frequency domain according to the task force guidelines of 1996 [5]. In the time domain, the standard deviation of RR-intervals (SDNN) and the square root of the mean of the sum of the squares of the difference between adjacent intervals (RMSSD) were selected for statistical analysis. Fast Fourier Transform was used to obtain the power spectral density of the HR. High frequency (HF) was defined as $0.15-0.4 \mathrm{~Hz}$ and low frequency (LF) was defined as $0.04-0.15$ $\mathrm{Hz}$. The result was expressed in normalized units (n.u.) and in LF/HF ratio.

Maximal power (W) from the interrupted levels of the exercise test was calculated according to Strandell as follows:

$$
(\text { Maximal power })=(\text { Submaximal power })+\left(25^{\star} n / 4\right)
$$

Where submaximal power is the power expressed in $\mathrm{W}$ on the level below the interrupted level, and $\mathrm{n}$ is the number of minutes completed at the highest level [26].

HR recovery is defined as the difference between the highest achieved HR and the HR 1, 2, 4, 10, 15 and 20 minutes after the 
Citation: Lange E, Mannerkorpi K, Cider A, Archer T, Wentz K (2017) Physiological Adaptation in Women Presenting Fibromyalgia: Comparison with Healthy Controls. Clin Exp Psychol 3: 147. doi: 10.4172/2471-2701.1000147

test. For the statistical analysis the statistical package for the social sciences (version 22, 2013 SPSS Inc., Chicago, IL, USA) was used. For comparisons of HR unpaired Student's t test with two-tailed significance was used. Non-parametric Mann-Whitney U test was used when the data was not normally distributed and for ordinal-level data. To decide if data was normally distributed Shapiro-Wilk's test was performed and a $\mathrm{z}$-value between -1.96 and +1.96 for skewness and kurtosis was sought for normality [27]. Data is reported as mean \pm SD or median and range. The significance level was set at an alpha $<0.05$. In a further step a correlative examination was performed group wise regarding residuary variables where women with fibromyalgia significantly differed from healthy women. The amount of variables was restricted through formation of sum variables concerning successive levels of workload. In order also to determine the relationship between predictor variables other than HRV and the HR response to exercise a linear regression analysis, using the enter method with the HR sum variable as the criterion variable, was performed. The predictor variables were chosen among the variables where women with fibromyalgia significantly differed from healthy women. The analyses were performed for the study group and the healthy controls separately. A further consideration was that both groups retained an acceptable size (around 20 participants) through both types of calculations. The number of predictor variables in the regression analysis was adapted by group size. In both types of calculations the level of significance was .05 two-tailed.

\section{Results}

\section{Subjects}

Twenty-five women with FM were referred to the study, of which one was excluded due to another condition listed in the exclusion criteria. Twenty-nine healthy women were examined and 26 of them were included in this study to achieve age matching ( \pm 3 years).

The characteristics of the subjects are shown in Table 1. There was a significant difference between the groups in self-rated physical activity (PHA) on the Saltin-Grimby Physical Activity Level Scale; a larger number of women with FM were inactive and did not perform moderate to vigorous physical activity to the same extent as the healthy referencegroup $(\mathrm{p}=0.019)$. However, the level of physical activity measured with the Godin Leisure-Time Exercise Questionnaire did not differ between the groups. There was no difference in education level between the groups; $72.7 \%$ of the women with FM and $72 \%$ of the healthy reference group had more than twelve years of education. In the eight specific domains of SF 36 as well as in the two summarized scores for physical (PCS) and mental components (MCS) the women with FM had significantly lower $(\mathrm{p}<0.001)$ results compared to the healthy reference group (Table 1).

\section{HRV}

In Table 2 the differences in HRV at baseline and post-test is shown.

Difference between groups at baseline: At baseline no significant differences between the groups were seen in any of the HRV-parameters.

Change within groups: No difference from baseline to post-test was found in the parameters of HRV within the group with FM. The healthy reference group showed a significant difference in every studied HRV-parameter: a reduction in HF n.u., SDNN and RMSSD after the exercise test.

Difference between groups for change from baseline to posttest: There was a significant difference between groups in how the RMSSD parameter was affected by the test; post-test the women with

\begin{tabular}{|c|c|c|c|}
\hline & $F M(n=24)$ & Reference group $(n=26)$ & p-value \\
\hline & Mean \pm SD & Mean \pm SD & \\
\hline Age (years) & $49.4 \pm 9.8$ & $48.7 \pm 9.0$ & 0.799 \\
\hline BMI $\left(\mathrm{kg} / \mathrm{m}^{2}\right)$ & $27.3 \pm 6.0$ & $25.1 \pm 3.0$ & 0.113 \\
\hline \multirow[t]{2}{*}{ Pain duration (years) } & $12.7 \pm 9.6$ & NA & \\
\hline & Median(min-max) & Median(min-max) & \\
\hline Pain VAS (mm) & $40(0-99)$ & NA & \\
\hline \multicolumn{4}{|l|}{ SF36 $(n=22 / 25)$} \\
\hline Physical component summary & $29(19-40)$ & $55(33-61)$ & $<0.001$ \\
\hline \multirow[t]{2}{*}{ Psychological component summary } & $29(11-52)$ & $52(33-65)$ & $<0.001$ \\
\hline & $n(\%)$ & $n(\%)$ & \\
\hline Education $(n=22 / 25)$ & & & 0.967 \\
\hline$\leq 9$ years & $1(4.5 \%)$ & $1(4 \%)$ & \\
\hline $9-12$ years & $5(22.7 \%)$ & $6(24 \%)$ & \\
\hline$>12$ years & $16(72.7 \%)$ & $18(72 \%)$ & \\
\hline Godin, weekly leisure activity $(n=20 / 23)$ & $21(0-57.5)$ & $33(8-67)$ & 0.059 \\
\hline Godin, frequency of sweat-inducing exercise & & & 0.127 \\
\hline Never/rarely & $9(45 \%)$ & $7(30.4 \%)$ & \\
\hline Sometimes & $8(40 \%)$ & $7(30.4 \%)$ & \\
\hline Often & $3(15 \%)$ & $9(39.1 \%)$ & \\
\hline Saltin-Grimby physical activity $(n=22 / 24)$ & & & 0.019 \\
\hline Inactive & $7(31.8 \%)$ & $2(8.3 \%)$ & \\
\hline Light physical activity & $11(50 \%)$ & $11(45.8 \%)$ & \\
\hline Moderate physical activity & $3(13.6 \%)$ & $9(37.5 \%)$ & \\
\hline Vigorous physical activity & $1(4.5 \%)$ & $2(8.3 \%)$ & \\
\hline
\end{tabular}

Note: Values are given as mean \pm standard deviation (SD), median (range) and number (percentages).

BMI: Body Mass Index; VAS: Visual Analog Scale; NA: Not Applicable; SF36: Short Form 36 Health Survey

Table 1: Demographic characteristics among FM patients and healthy controls. 
Citation: Lange E, Mannerkorpi K, Cider A, Archer T, Wentz K (2017) Physiological Adaptation in Women Presenting Fibromyalgia: Comparison with Healthy Controls. Clin Exp Psychol 3: 147. doi: 10.4172/2471-2701.1000147

Page 4 of 8

\begin{tabular}{|c|c|c|c|c|c|c|c|c|}
\hline \multicolumn{4}{|c|}{$F M(n=21)$} & \multicolumn{3}{|c|}{ Healthy controls $(n=25)$} & \multicolumn{2}{|c|}{ Between groups $P$} \\
\hline Baseline & Baseline & Post test & $p$-value & Baseline & Post test & p-value & pre test & post test \\
\hline HF n.u. & $34.16 \pm 15.5$ & $31.09 \pm 20.95$ & 0.467 & $43.72 \pm 20.2$ & $26.81 \pm 15.96$ & 0.001 & 0.105 & 0.604 \\
\hline LF/HF & $2.77 \pm 2.32$ & $3.88 \pm 3.52$ & 0.467 & $1.88 \pm 1.53$ & $4.27 \pm 4.01$ & 0.001 & 0.105 & 0.604 \\
\hline SDNN & $58.69 \pm 47.05$ & $52.64 \pm 61.31$ & 0.339 & $39.82 \pm 15.55$ & $29.88 \pm 13.21$ & 0.017 & 0.168 & 0.069 \\
\hline RMSSD & $37.39 \pm 49.0$ & $45.18 \pm 104.15$ & 0.652 & $29.37 \pm 18.08$ & $14.69 \pm 8.27$ & 0.000 & 1.620 & 0.189 \\
\hline
\end{tabular}

Note: Values are given as mean \pm standard deviation.

LF n.u.: Low Frequency Power in Normalized Units; HF: High Frequency; SDNN: Standard Deviation of NN Intervals; RMSSD: Root Mean of the Sum of the Squares of the Differences Between Adjacent NN Intervals

Table 2: Heart rate variability at baseline and after submaximal exercise test among FM patients and healthy controls.

FM showed a slightly increased RMSSD on average $(+7.78 \mathrm{~ms})$ and the healthy reference group showed a reduction of $14.68 \mathrm{~ms}(\mathrm{p}=0.013)$. No significant difference was present for the change in any other HRVparameter between the two groups.

Difference between groups post-test: No significant difference between the groups was seen regarding the HRV-parameters post-test.

\section{Outliers}

One of the women with FM showed extreme values in time domain measures which were the source of the large standard deviations of these parameters. Calculations with this subject excluded did slightly change the p-value, however it did not change weather each separate parameter analysis was significant or not. Analysis of HRV with the one outlier excluded resulted in a lower mean SDNN and RMSSD for the women with FM at baseline and post-test (Table 2).

\section{HR}

The women with FM had a significantly higher HR than the healthy reference group at baseline (Table 3 ).

The average HR at each specific workload which at least 13 people of each group completed and the achieved workload at peak is shown in Table 3. The women with FM had a significantly higher HR than the healthy reference group at each workload up to $75 \mathrm{~W}$ both in absolute and in relative figures. The rated Borg RPE was significantly different between groups during the test but at peak there were no difference.

The women with FM had a significantly lower peak HR and reached significantly lower workloads at peak than the healthy reference group. A slower HR recovery was seen among the women with FM compared to the healthy reference group in all measurement from 2-20 minutes (Table 3).

In order for both study groups to remain at level around 20 participants the values concerning HR and RPE at $75 \mathrm{~W}$ and $87 \mathrm{~W}$ where excluded. Appurtenant values concerning $\mathrm{HR}$ at peak and relative $\mathrm{HR}$ as \% of peak were also excluded. After that the correlations between variables other than HRV where women with fibromyalgia significantly differed from healthy women namely HR2 (sum variable of HR $25 \mathrm{~W}+\mathrm{HR} 50 \mathrm{~W}$ ), HRR20 (sum variable of HRR measurents during 20 minutes), RPE 2 (sum variable RPE during $25 \mathrm{~W}+\mathrm{RPE} 50$ W), including also Saltin-Grimby Physical Activity (PhA), PCS and MCS was performed group wise (Tables 4 and 5).

Women with $\mathrm{F}$ showed fewer correlative links between measurements than the controls. The observational data of HR2 correlated with the observational data of heart rate recovery over 20 minutes (HRR20). HRR20 correlated negatively with Rated Physical
Exertion during 25 and $50 \mathrm{~W}$ (RPE2). In the group of healthy controls HR2 correlated with HRR20 but also negatively with $\mathrm{PhA}$. In turn PhA correlated negatively with RPE2. In the group of controls PCS and MCS showed a significant negative correlation (Tables 6 and 7).

A linear regression analysis enter method was performed groupwise with HR2 as the criterion variable. Regarding women with $\mathrm{F}$ a significant multiple regression equation was found $\mathrm{F}(3,15)=6.220$, $\mathrm{p}=0.002$. An adjusted $\mathrm{R}$ square explained 0.465 of the variance in HR2 from 2 out of 3 predictors. The significant predictors of HRR20 and and RPE2 reached significant Beta values of 0.841 with a $p$ value of 0.002 and 0.494 with a p value of 0.041 respectively. Concerning healthy women a significant regression equation was found $F(3,20)=7.232$, $p=0.002$. An adjusted R Square explained 0.448 of the variance in HR2 from 2 out of 3 predictors. The significant predictors were HHR20 and $\mathrm{PhA}$ with Beta values of 0.554 with a $\mathrm{p}$ value of 0.002 and -0.390 with a $\mathrm{p}$ value of 0.035 repectively.

\section{Discussion}

FM patients differed markedly from the healthy control group with regard to physical and psychological components, their relative levels of physical exercise and a wide range of heart rate parameters during rest (baseline), and physical exercise testing and recovery.

\section{HRV}

The women presenting FM in the present study did not display any difference in HRV between baseline and post-test values. Contrastingly, the healthy control group was affected markedly by the physical exercise test over every HRV parameter; a reduction in both the time-domain parameters as well as HRV is observed during submaximal exercise testing in both women and men and gradually returns to resting values during recovery [28,29]. In young, healthy subjects HRV remains affected 15-25 minutes after both submaximal exercise tests and resistance training. Casonatto et al. [29] have stated that the length and intensity of the exercise affects the outcome and have only observed this effect with regard to the RMSSD [29-31]. The differences pertaining to how the FM patients and the healthy controls react to the exercise test in HRV should be noteworthy since HRV has not previously been studied during recovery in FM patients. Furthermore it may be suggested that women with $\mathrm{F}$ while not being significantly affected in any HRV parameter failed to physiologically adapt to exercise load.

Certain HRV parameters did not differ betwee the groups: Neither at baseline nor following the exercise test were there any differences in the HRV parameters between the two groups. Several previous studies have shown a deviant HRV in FM patients compared with healthy subjects, especially in the time-domain measures but also in 
Citation: Lange E, Mannerkorpi K, Cider A, Archer T, Wentz K (2017) Physiological Adaptation in Women Presenting Fibromyalgia: Comparison with Healthy Controls. Clin Exp Psychol 3: 147. doi: 10.4172/2471-2701.1000147

Page 5 of 8

\begin{tabular}{|c|c|c|c|}
\hline & FM $(n=24$ & Healthy Controls $(n=26)$ & $\mathrm{p}$-value \\
\hline $\mathrm{HR}$ at rest (bpm) & $70 \pm 10$ & $63 \pm 8$ & 0.018 \\
\hline \multicolumn{4}{|c|}{ HR during test (bpm) } \\
\hline $25 \mathrm{~W}$ & $95 \pm 10(n=24)$ & $87 \pm 9(n=26)$ & 0.004 \\
\hline $50 \mathrm{~W}$ & $111 \pm 13(n=23)$ & $98 \pm 10(n=26)$ & $<0.001$ \\
\hline $75 W$ & $129 \pm 17(n=16)$ & $115 \pm 15(n=26)$ & 0.005 \\
\hline $87.5^{1} \mathrm{~W}$ & $140 \pm 17(n=13)$ & $130 \pm 16(n=25)$ & 0.068 \\
\hline \multicolumn{4}{|c|}{ Relative HR during test (\% of peak) } \\
\hline $25 \mathrm{~W}$ & $70 \pm 12 \%$ & $58 \pm 6 \%$ & $<0.001$ \\
\hline $50 \mathrm{~W}$ & $80 \pm 11 \%$ & $65 \pm 7 \%$ & $<0.001$ \\
\hline $75 \mathrm{~W}$ & $89 \pm 11 \%$ & $76 \pm 9 \%$ & $<0.001$ \\
\hline $87.5^{1} \mathrm{~W}$ & $95 \pm 9 \%$ & $85 \pm 9 \%$ & 0.003 \\
\hline \multicolumn{4}{|c|}{ Rated exertion (Borg) } \\
\hline $25 \mathrm{~W}$ & $10(7-18)$ & $7.5(6-12)$ & 0.003 \\
\hline $50 \mathrm{~W}$ & $13(8-20)$ & $11(7-15)$ & $<0.001$ \\
\hline $75 \mathrm{~W}$ & $15(12-17)$ & $13(7-17)$ & 0.010 \\
\hline $87.5^{1} \mathrm{~W}$ & $17(13-20)$ & $15(7-19)$ & 0.003 \\
\hline Peak & $17(17-20)$ & $18(17-20)$ & 0.652 \\
\hline HR at peak (bpm) & $138 \pm 21$ & $152 \pm 13$ & 0.008 \\
\hline Workload at peak (W) & $82 \pm 25$ & $122 \pm 23$ & $<0.001$ \\
\hline \multicolumn{4}{|c|}{ HR recovery (bpm) } \\
\hline 1 minute & $-43 \pm 19$ & $-50 \pm 9$ & 0.127 \\
\hline 2 minutes & $-53 \pm 20$ & $-65 \pm 12$ & 0.018 \\
\hline 4 minutes & $-57 \pm 16$ & $-70 \pm 12$ & 0.002 \\
\hline 10 minutes & $-60 \pm 17$ & $-74 \pm 11$ & 0.001 \\
\hline 15 minutes & $-63 \pm 17$ & $-77 \pm 12$ & 0.002 \\
\hline 20 minutes & $-65 \pm 17$ & $-79 \pm 15$ & 0.003 \\
\hline
\end{tabular}

Note: Values are given as mean \pm standard deviation or median (range).

HR: Heart Rate; BPM: Beats Per Minute

${ }^{1} \mathrm{HR}$ after 2 minutes of $100 \mathrm{~W}$ according to Strandell [26].

Table 3: HR at baseline, during the test and at recovery among FM patients and healthy controls.

\begin{tabular}{|c|c|c|c|c|c|c|}
\hline & HR2 & HRR20 & RPE2 & PCS & MCS & PhA \\
\hline HR2 & 1 & $0.633^{* *}$ & -0.138 & -0.075 & -0.263 & 0.368 \\
\hline Sig. (2-tailed & & 0.033 & 0.551 & 0.761 & 0.276 & 0.110 \\
\hline $\mathbf{N}$ & 21 & 20 & 21 & 19 & 19 & 20 \\
\hline HRR20 & $0.633^{* *}$ & 1 & $-0.557^{\star \star}$ & 0.285 & -0.021 & 0.165 \\
\hline Sig. (2-tailed & 0.003 & & 0.009 & 0.237 & 0.933 & 0.487 \\
\hline $\mathbf{N}$ & 20 & 22 & 21 & 19 & 19 & 20 \\
\hline RPE2 & -0.138 & $-0.557^{* *}$ & 1 & -0.385 & -0.269 & -0.281 \\
\hline Sig. (2-tailed & 0.551 & 0.009 & & 0.093 & 0.252 & 0.217 \\
\hline $\mathbf{N}$ & 21 & 21 & 22 & 20 & 20 & 21 \\
\hline PCS & -0.075 & 0.285 & -0.385 & 1 & -0.314 & 0.147 \\
\hline Sig. (2-tailed & 0.761 & 0.237 & 0.093 & & 0.165 & 0.525 \\
\hline $\mathbf{N}$ & 19 & 19 & 20 & 21 & 21 & 21 \\
\hline MCS & -0.263 & -0.021 & -0.269 & -0.314 & 1 & 0.121 \\
\hline Sig. (2-tailed & 0.276 & 0.933 & 0.252 & 0.165 & & 0.600 \\
\hline $\mathbf{N}$ & 19 & 19 & 20 & 21 & 21 & 21 \\
\hline PhA & 0.368 & 0.165 & -0.281 & 0.147 & 0.121 & 1 \\
\hline Sig. (2-tailed & 0.110 & 0.487 & 0.217 & 0.525 & 0.600 & \\
\hline $\mathbf{N}$ & 20 & 20 & 21 & 21 & 21 & 22 \\
\hline
\end{tabular}

Note: ${ }^{* *}$ Correlation is significant at the 0.01 level. ${ }^{*}$ Correlation is significant at the 0.05 level.

Table 4: Correlations between heart rate HR2 (sum variable HR 25+HR 50W), heart rate recovery HRR20 (sum variable of measurements during 20 minutes), Rated Physical Exertion RPE2 (sum variable RPE 25+RPE 50W), Physical Component from SF-36 (PCS), Mental Component from SF-36 (MCS) and Physical Activity (PhA) in women presenting FM. 


\begin{tabular}{|c|c|c|c|c|c|c|}
\hline & HR2 & HRR20 & RPE2 & PCS & MCS & PhA \\
\hline HR2 & 1 & $0.508^{* *}$ & 0.286 & 0.369 & -0.339 & $-0.471^{*}$ \\
\hline Sig. (2-tailed & & 0.008 & 0.156 & 0.100 & 0.132 & 0.020 \\
\hline $\mathbf{N}$ & 26 & 26 & 26 & 21 & 21 & 24 \\
\hline HRR20 & $0.508^{* *}$ & 1 & -0.138 & 0.372 & -0.277 & -0.015 \\
\hline Sig. (2-tailed & 0.008 & & 0.501 & 0.097 & 0.223 & 0.945 \\
\hline $\mathbf{N}$ & 26 & 26 & 26 & 21 & 21 & 24 \\
\hline RPE2 & 0.286 & -0.138 & 1 & -0.027 & -0.260 & $-0.434^{*}$ \\
\hline Sig. (2-tailed & 0.156 & 0.501 & & 0.906 & 0.256 & 0.034 \\
\hline $\mathbf{N}$ & 26 & 26 & 26 & 21 & 21 & 24 \\
\hline PCS & 0.369 & 0.372 & -0.027 & 1 & $-0.573^{* *}$ & 0.023 \\
\hline Sig. (2-tailed & 0.100 & 0.097 & 0.906 & & 0.007 & 0.924 \\
\hline $\mathbf{N}$ & 21 & 21 & 21 & 21 & 21 & 20 \\
\hline MCS & -0.339 & -0.277 & -0.260 & $-0.573^{* *}$ & 1 & 0.094 \\
\hline $\begin{array}{c}\text { Sig. (2-tailed } \\
\mathrm{N}\end{array}$ & $\begin{array}{c}0.132 \\
21\end{array}$ & $\begin{array}{c}0.223 \\
21\end{array}$ & $\begin{array}{c}0.256 \\
21\end{array}$ & $\begin{array}{c}0.007 \\
21\end{array}$ & 21 & 0.69220 \\
\hline PhA & $-0.471^{*}$ & -0.015 & $-0.434^{*}$ & 0.023 & 0.094 & 1 \\
\hline Sig. (2-tailed & 0.020 & 0.945 & 0.034 & 0.924 & 0.692 & \\
\hline $\mathbf{N}$ & 24 & 24 & 24 & 20 & 20 & 24 \\
\hline
\end{tabular}

Note: **Correlation is significant at the 0.01 level. * Correlation is significant at the 0.05 level.

Table 5: Correlations between HR2 (sum variable HR 25W+HR 50W), HRR20 (sum variable of HRR measurements during 20 minutes), RPE2 (sum variable RPE 25W+RPE 50W), Physical Component from SF-36 (PCS), Mental Component from SF-36 (MCS) and Physical Activity (PhA) in healthy controls.

\begin{tabular}{c|c|c|c|c|c|}
\hline Model & $\mathbf{R}$ & R Square & Adjusted R Square & Std. Error of the Estimate \\
\hline 1 & 0.745 & 0.554 & 0.465 & 15.77526
\end{tabular}

Table 6: A linear regression analysis using the enter method with HR2 (sum variable $25+50 \mathrm{~W}$ ) as the criterion variable and two other variables from physiological testing namely Rated Physical Exertion during 25 and 50 W (RPE2) and HRR20 (sum variable of HRR measurements during 20 minutes) as predictors together with Physical Activity (PhA) concerning women with FM.

\begin{tabular}{|c|c|c|c|}
\hline Model & R & R Square & Adjusted R Square \\
\hline 1 & 0.721 & 0.520 & 0.448 \\
\hline
\end{tabular}

Table 7: A linear regression analysis enter method with HR2 (sum variable $25+50 \mathrm{~W}$ ) as the criterion variable and two other variables recorded during physiological testing namely Rated Physical Exertion during 25 and 50 W (RPE2) and HRR20 (sum variable of HRR measurements during 20 minutes) as predictors together with Physical Activity (PhA) concerning healthy controls.

the frequency-domain [3,4,8,32]. In the review by Meeus et al. [33], a similar result was observed but in a meta-analysis from 2009 by Tak et al. [34] this difference did not reach significance for a subgroup of FM patients although the difference was significant for a compound group with functional somatic disorders. Interestingly, Tak et al. [34] also reported a varying quality in the conducted studies and a large variety in the methods used to measure and analyze HRV, which makes the comparison of the results difficult.

In the present study, large standard deviations concerning all the measured variables as well as the direction and magnitude of change during testing were observed by both groups. These variations may have been the result of several parameters affecting HRV; the variations displayed by the FM patients may be expected given the intricacies of their condition. These parameters included, amongst other variables: age, gender, physical health functioning, menstrual cycle, smoking, pain sensations, physical exercise propensities, affective status and anxiety $[32,35]$. Nevertheless, the present participants, FM patients and healthy controls, were matched only with regard to gender and age out of the possible factors involved with the healthy control group reporting a very low level of pain. Lampman [36] suggests that the reference groups used for comparison with FM ought to be matched, not only in age and gender, but also for reported levels of pain, fatigue and depression. The subjects in the present study were matched for educational level which is assumed to have certain links with health-related quality of life [37]. Nevertheless, the SF-36 instrument, which provides a measure of physical and psychological health, showed significant differences between the two groups. The measure of HRV is affected also by methodological issues, such as temperature of the examination room and breathing frequency which were not taken under consideration when conducting the present study [34].

The use of HRV for monitoring sports training and optimizing exercise load has not yet been sufficiently examined. It has been suggested that changes in HRV may offer useful parameters for managing physical fatigue and exercise intensity [38]. Further validation of these notions may be beneficial for physiotherapists since physical fatigue and intensity of exercise strongly affect the outcome of physiotherapeutic exercise interventions for FM patients [12]. Nevertheless, despite prevailing conjectures concerning the implications of HRV in sports contexts, HRV fails to describe all aspects of wellness, fatigue and performance [39]. Hence, the accumulated professional competence of physiotherapist-interventions ought to be recruited for the provision of finesse in the exercise prescription for FM patients [12].

\section{HR}

There were no indications that the HR responses were linked to chronotropic incompetence, the inability of the heart to increase its rate commensurate with increased activity or demand, among the FM patients, since their HR was higher than the healthy control group with comparable workloads. Bardal et al. [17] have shown that a submaximal exercise test may not be sufficient to detect chronotropic incompetence 
in FM patients. This observation is concordant with Van Denderen et al. [16] who found differences between groups at workloads above $80 \mathrm{~W}$. No analysis intended to detect chronotropic incompetence is possible to perform in any accurate way in the absence of information about maximum HR. For clinical purposes, it would have been of interest to be able to detect tendencies for chronotropic incompetence from a submaximal test although from the present study result this purpose remains unfeasible. The FM patients in the present study were only able to perform exercise up to an average of $82 \mathrm{~W}$ before the rated exertion achieved extreme levels while the healthy control group maintained the ability to continue performing up to an average of $122 \mathrm{~W}$. This observation implies that FM patients may experience difficulty in the performance of particular physical activity and exercise programs designed for healthy women. For FM patients to be able to exercise on a moderate to high intensity (the Borg scale: RPE 15) without increased pain, 2 minute interval training has been shown to be appropriate [40].

The situation that participants in the study were not perfectly matched for physical activity levels may have influenced the outcome. The FM patients were inactive to a greater extent than the healthy control group and not as engaged in moderate physical activity as the latter. Fitness level is strongly correlated to HR but only partially to HRV [41,42]. Among healthy women an increased HR on each completed level of exercise was correlated with a lower fitness level [43]; this pattern confirmed also in the present results wherein HR in healthy women correlated with physical activity whereas FM patients failed to present the same relationship between $\mathrm{HR}$ and exercise thereby differing from the former. This finding implies in FM wider difficulties of ANS adaptation that relates to the aforementioned failure to alter autonomic modulation from exercise [13]. An altogether analogous pattern regarding a positive effect on FM symptoms but failure improving autonomous modulation was found from biofeedback training. Only the healthy controls showed an effect from training on autonomic modulation [44]. In the present study, rated exertion seemed to replace an adaptive effect from physical exercise on HR during loading from exercise. As expected, physical exercise was adaptively, i.e., negatively, related to RPE in healthy women but not in in the FM patients. Irrespective of age fitness is manifested as parasympathetic influence during load in healthy individuals [43] In F this influence from fitness is missing.

The women with FM rated their exertion on Borg higher during the test and 17 on Borg RPE at a significantly lower HR than the healthy reference group. Also in a study of patients with low back pain neither pain, disability, kinesiophobia nor depression were related to the accuracy of Borg RPE in relation to HR [45]. The same seem to apply to women with FM since from the present examination was found that RPE was not related to any pain measures. Instead pain measures from SF-36 and from the test were related to HR during load from exercise. In this respect also intermittent $F$ pain $[46,47]$ was related to $H R$ during exercise while women with breaks in $\mathrm{F}$ pain presented a HR more similar to that of healthy controls.

The mean age and the general health assessed by SF36 on the studied sample is similar to that of women presenting FM in previous studies carried out in the region of Västra Götaland (Sweden) implying that the sample studied is representative for FM women in the region $[48,49]$.

HRV is said to measure the function of the ANS but the understanding of the physiological meaning of HRV is incomplete [50]. The method for measuring HRV in the present study can be questioned, especially in women. The use of basic heart rate monitors has gained in popularity and is easy to use clinically but the appurtenant methodology for identification of artifacts and abnormal heartbeats is unsatisfying and affects the entire analyze of HRV [51]. The large number of uncertain factors and methodological difficulties in standardizations of the test, mentioned above, also contribute to the hesitation for clinical use so far [34].

\section{Conclusion}

We have concluded that the HRV in women presenting FM is not significantly affected by submaximal exercise to the same extent as the HRV of healthy women. For physiotherapeutic interventions, it ought to borne in mind that FM women seem to rate exertion "Very hard" on lower workload and HR than healthy women. Moreover, FM women display less adjustment of the ANS while not being significantly affected by submaximal exercise as healthy women. In healthy women, HR during $25 \mathrm{~W}$ and $50 \mathrm{~W}$ was negatively related to $\mathrm{PhA}$ and also to RPE. In women with FM HR was unrelated to $\mathrm{PhA}$ but positively related to RPE. Exertion seems to replace an effect from exercise on physiological adaptation in FM a condition that may entail imperceptible extraction of power from $\mathrm{PhA}$ while under load. The unresponsiveness of the ANS and the cardiovascular system to exercise may hold explanatory possibilities regarding clinical pain in FM.

\section{Acknowledgements}

The present study was founded by the local research and development council of Gothenburg. Thanks to Filip Lange, M. Sc. for technical advice.

\section{References}

1. Coster L, Kendall S, Gerdle B, Henriksson C, Henriksson KG et al. (2008) Chronic widespread musculoskeletal pain - a comparison of those who meet criteria for fibromyalgia and those who do not. Eur J Pain 12: 600-610.

2. Wolfe F, Smythe HA, Yunus MB, Bennett RM, Bombardier C, et al. (1990) The american college of rheumatology 1990 criteria for the classification of fibromyalgia. Report of the Multicenter Criteria Committee. Arthritis Rheum 33: 160-172.

3. Kulshreshtha P, Gupta R, Yadav RK, Bijlani RL, Deepak KK (2012) A comprehensive study of autonomic dysfunction in the fibromyalgia patients. Clin Auton Res 22: 117-122.

4. Lerma C, Martinez A, Ruiz N, Vargas A, Infante O, et al. (2011) Nocturnal heart rate variability parameters as potential fibromyalgia biomarker: correlation with symptoms severity. Arthritis Res Ther 13: R185.

5. Malik M, Bigger JT, Camm AJ, Kleiger RE, Malliani A, et al. (1996) Heart rate variability: Standards of measurement, physiological interpretation, and clinical use. Eur Heart J 17: 354-381.

6. Da Cunha Ribeiro RP, Roschel H, Artioli GG, Dassouki T, Perandini LA, et al. (2011) Cardiac autonomic impairment and chronotropic incompetence in fibromyalgia. Arthritis Res Ther 13: 190.

7. Reyes Del Paso GA, Garrido S, Pulgar A, Martin-Vazquez M, Duschek S (2010) Aberrances in autonomic cardiovascular regulation in fibromyalgia syndrome and their relevance for clinical pain reports. Psychosom Med 72: 462-470.

8. Mork PJ, Nilsson J, Loras HW, Riva R, Lundberg U (2013) Heart rate variability in fibromyalgia patients and healthy controls during non-REM and REM sleep: a case-control study. Scand J Rheumatol 42: 505-508.

9. Meeus M, Goubert D, De Backer F, Struyf F, Hermans L (2013) Heart rate variability in patients with fibromyalgia and patients with chronic fatigue syndrome: a systematic review. Semin Arthritis Rheum 43: 279-287.

10. Busch AJ, Webber SC, Brachaniec M, Bidonde J, Bello-Haas VD, et al. (2011) Exercise therapy for fibromyalgia. Curr Pain Headache Rep 15: 358-367.

11. Gavi MB, Vassalo DV, Amaral FT, Macedo DC, Gava PL, et al. (2014) Strengthening exercises improve symptoms and quality of life but do not change autonomic modulation in fibromyalgia: A randomized clinical trial. PLoS One 20: e90767.

12. Nijs J, Mannerkorpi K, Descheemaeker F, Van Houdenhove B (2010) Primary care physical therapy in people with fibromyalgia: opportunities and boundaries within a monodisciplinary setting. Phys Ther 90: 1815-1822. 
Citation: Lange E, Mannerkorpi K, Cider A, Archer T, Wentz K (2017) Physiological Adaptation in Women Presenting Fibromyalgia: Comparison with Healthy Controls. Clin Exp Psychol 3: 147. doi: 10.4172/2471-2701.1000147

13. Hwang IS, Noh YS, Jeong IC, Yoon HR (2011) Optimized exercise load control system based on heart rate variability. Biomed Eng Lett 1: 232-238.

14. Camm AJ, Fei L (1996) Chronotropic incompetence--Part I: Normal regulation of the heart rate. Clin Cardiol 19: 424-428.

15. Brubaker PH, Kitzman DW (2011) Chronotropic incompetence: causes, consequences, and management. Circulation 123: 1010-1020.

16. Van Denderen JC, Boersma JW, Zeinstra P, Hollander AP, van Neerbos BR (1992) Physiological effects of exhaustive physical exercise in primary fibromyalgia syndrome (PFS): is PFS a disorder of neuroendocrine reactivity? Scand J Rheumatol 21: 35-37.

17. Bardal EM, Olsen TV, Ettema G, Mork PJ (2013) Metabolic rate, cardiac response, and aerobic capacity in fibromyalgia: a case-control study. Scand J Rheumatol 42: 417-420.

18. Ware JE, Gandek B (1998) Overview of the SF-36 Health Survey and the International Quality of Life Assessment (IQOLA) project. J Clin Epidemiol 51: 903-912.

19. Assumpcao A, Pagano T, Matsutani LA, Ferreira EA, Pereira CA, et al. (2010) Quality of life and discriminating power of two questionnaires in fibromyalgia patients: Fibromyalgia impact questionnaire and medical outcomes study 36item short-form health survey. Rev Bras Fisioter 14: 284-289.

20. Godin G, Shephard RJ (1985) A simple method to assess exercise behavior in the community. Can J Appl Sport Sci 10:141-147.

21. Rodjer L, Jonsdottir IH, Rosengren A, Bjorck L, Grimby G, et al. (2012) Selfreported leisure time physical activity: a useful assessment tool in everyday health care. BMC Public Health 12: 693.

22. Aires N, Selmer R, Thelle D (2003) The validity of self-reported leisure time physical activity, and its relationship to serum cholesterol, blood pressure and body mass index. A population based study of 332,182 men and women aged 40-42 years. Eur J Epidemiol 18: 479-485.

23. Helmerhorst HJ, Brage S, Warren J, Besson H, Ekelund U (2012) A systematic review of reliability and objective criterion-related validity of physical activity questionnaires. Int J Behav Nutr Phys Act 9: 103.

24. Weippert M, Kumar M, Kreuzfeld S, Arndt D, Rieger A, et al. (2010) Comparison of three mobile devices for measuring R-R intervals and heart rate variability: Polar S810i, Suunto t6 and an ambulatory ECG system. Eur J Appl Physiol 109: 779-786.

25. Borg G (1998) Borg's Perceived exertion and pain scales: Human kinetics

26. Strandell T (1964) Circulatory studies on healthy old men with special reference to the limitation of the maximal physical working capacity. Acta Med Scand Suppl 414: 1-44.

27. Razali NM, Wah YB (2011) Power comparisons of Shapiro-Wilk, KolmogorovSmirnov, Lilliefors and Anderson-Darling tests. Journal of Statistical Modeling and Analytics 2: 21-33.

28. Correa FR, Da Silva Alves MA, Bianchim MS, Crispim de Aquino A, Guerra RL, et al. (2013) Heart rate variability during 6-min walk test in adults aged 40 years and older. Int J Sports Med 34: 111-115.

29. Casonatto J, Tinucci T, Dourado AC, Polito M (2011) Cardiovascular and autonomic responses after exercise sessions with different intensities and durations. Clinics (Sao Paulo) 66: 453-458.

30. Barak OF, Jakovljevic DG, Popadic Gacesa JZ, Ovcin ZB, Brodie DA, et al. (2010) Heart rate variability before and after cycle exercise in relation to different body positions. J Sports Sci Med 9: 176-182.

31. Heffernan KS, Kelly EE, Collier SR, Fernhall B (2006) Cardiac autonomic modulation during recovery from acute endurance versus resistance exercise. Eur J Cardiovasc Prev Rehabil 13: 80-86.

32. Mostoufi SM, Afari N, Ahumada SM, Reis V, Wetherell JL (2012) Health and distress predictors of heart rate variability in fibromyalgia and other forms of chronic pain. J Psychosom Res 72: 39-44.
33. Meeus M, Goubert D, De Backer F, Struyf F, Hermans L, et al. (2013) Heart rate variability in patients with fibromyalgia and patients with chronic fatigue syndrome: a systematic review. Semin Arthritis Rheum 43: 279-287.

34. Tak LM, Riese H, de Bock GH, Manoharan A, Kok IC, et al. (2009) As good as it gets? A meta-analysis and systematic review of methodological quality of heart rate variability studies in functional somatic disorders. Biol Psychol 82: 101-110.

35. Bai X, Li J, Zhou L, Li X (2009) Influence of the menstrual cycle on nonlinear properties of heart rate variability in young women. Am J Physiol Heart Circ Physiol 297: H765-774.

36. Lampman JH (2014) What is the proper control group for a fibromyalgia study? Arthritis Rheumatol 66: 1684

37. Mielck A, Reitmeir P, Vogelmann M, Leidl R (2013) Impact of educational level on health- related quality of life (HRQL): results from Germany based on the EuroQol 5D (EQ-5D). Eur J Public Health 23: 45-49.

38. Makivic BWM, Nikic MD (2013) Heart rate variability (HRV) as a tool for diagnostic and monitoring performance in sport and physical activities. J Exerc Physiol 16: 103-131.

39. Buchheit M (2014) Monitoring training status with HR measures: do all roads lead to Rome? Front Physiol 5: 73.

40. Mannerkorpi K, Nordeman L, Cider A, Jonsson G (2010) Does moderate-to-high intensity Nordic walking improve functional capacity and pain in fibromyalgia? A prospective randomized controlled trial. Arthritis Res Ther 12: R189.

41. Grant CC, Murray C, Janse van Rensburg DC, Fletcher L (2013) A comparison between heart rate and heart rate variability as indicators of cardiac health and fitness. Front Physiol 4: 337.

42. Karavirta L, Costa MD, Goldberger AL, Tulppo MP, Laaksonen DE, et al. (2013) Heart rate dynamics after combined strength and endurance training in middleaged women: Heterogeneity of responses. PLoS One 8: e72664.

43. Tulppo MP, Makikallio TH, Seppanen T, Laukkanen RT, Huikuri HV (1998) Vagal modulation of heart rate during exercise: effects of age and physical fitness. Am J Physiol 274: H424-429.

44. Hasset AL, Radvanski DC, Vaschillo EG, Vaschillo B, Sigal LH, et al. (2007) A pilot study of the efficacy of heart rare variability (HRV) biofeedback in patients with fibromyalgia. Applied Psychochphysiology and Biofeedback 32: 1-10.

45. Demoulin C, Verbunt JA, Winkens B, Knottnerus JA, Smeets RJ (2010) Usefulness of perceived level of exertion in patients with chronic low back pain attending a physical training programme. Disabil Rehabil 32: 216-222.

46. Wentz KAH (2013) Symptom fluctuation in fibromyalgia. Environmental, psychological and psychobiological influences. DeGruyter, Berlin.

47. Henriksson KG (2002) Is fibromyalgia a central pain state? Muskuloskeletal pain 10: 45-57.

48. Andrell P, Schultz T, Mannerkorpi K, Nordeman L, Borjesson M, et al. (2014) Health-related quality of life in fibromyalgia and refractory angina pectoris: $A$ comparison between two chronic non-malignant pain disorders. J Rehabil Med 46: 341-347.

49. Palstam A, Bjersing JL, Mannerkorpi K (2012) Which aspects of health differ between working and nonworking women with fibromyalgia? A cross-sectional study of work status and health. BMC Public Health 12: 1076.

50. Lombardi $F$ (2002) Clinical implications of present physiological understanding of HRV components. Card Electrophysiol Rev 6: 245-249.

51. Wallen MB, Hasson D, Theorell T, Canlon B, Osika W (2012) Possibilities and limitations of the Polar RS800 in measuring heart rate variability at rest. Eur J Appl Physiol 112: 1153-1165. 